\title{
Yo, Neuróptico
}

Antonio Altarriba

Y llegó el tiempo de jugar con las palabras... Un poco después de empezar a jugar con las libertades, los derechos, las urnas y otras diversiones democráticas, hizo acto de presencia el desparrame verbal. Al menos así fue para mí. Siempre había sido sensible a las palabras, a su sonoridad rotunda, cavernosa, arisca, insinuante y, con frecuencia, significativamente confusa. Acabábamos de abandonar el léxico solemne, tan pomposo como vacío, del franquismo. Todavía resonaban en nuestras secuestradas entendederas aquellos significantes grandilocuentes, pero sin referente alguno. Conocemos la capacidad de la palabra para, a fuerza de repetirla, acabar creando la cosa. Pero los nacidos después de la guerra, educados en el miedo y el silencio, no entendíamos nada. Veníamos de una «Santa Cruzada» en la que fuimos guiados por un «hombre providencial» que, como no cabía en el generalato, le inventamos un «generalisimato». Vivíamos en «Una, Grande y Libre», rodeados de «Gloriosos Caídos por Dios y por España». Caminábamos «por el Imperio hacia Dios», de la mano de un tal «José Antonio». Levantábamos España en todo momento («iArriba!»). Y, a pesar de ello, nunca dejábamos de caer en el pecado, «de pensamiento, palabra, obra u omisión».

En aquellos años descubrí también que no estaba solo en la afición al juego verbal. Una rica tradición me acompañaba. Y esa tradición, practicada universalmente, tenía un brillante recorrido en nuestra literatura barroca. Me junté con otros palabreros y hasta entré en contacto con el Obrador de Literatura Potencial (OULIPO), en boga entonces en la literatura francesa. Así me infecté de palindromías, anagramemas, lipogramatizaciones, aliteraciones, calamburismos, paranomasias, retruecanitis, paradojenias, homofoniosis, tautogramías, redundamientos, metátesis, acrosticonías y otros males léxicos. En aquellos tiempos de compromiso, cantautor, palabras como balas y de tomar partido, partido hasta mancharse, los juegos de palabras se antojaban malabarismos verbales, ejercicios tan ingeniosos como gratuitos, incluso algo reaccionarios. Al fin y al cabo, se trataba de promover deslices lingüísticos, resbalones en la insignificancia, una forma de evasión más que de crítica política. Sin embargo, siempre pensé que había algo de revolucionario en ese cortocircuito comunicativo que conlleva el juego de palabras. En último término (quizá en primero), se trata de impedir que la palabra se relacione con la realidad a la que reenvía y se ensimisme en su 
esencia letrística y fonética. Supone extirpar su función nominativa para recrearse con su forma. El cuerpo por encima del espíritu de la letra. Quererla por lo que es y no por lo que dice. Así se denuncia la arbitrariedad de la lengua, se hace burla del código al que obedece y se reconoce que, al fondo de la gramática, en el trastero del diccionario, se encuentra, irreductible a cualquier pronunciamiento, lo indecible.

Así que no sólo era juego. El nombre de Neuróptica hacía eco al de Neurotica, una sesuda revista donde publicaba Fredric Wertham, el autor de La seducción del inocente y de otros estudios psiquiátricos en los que se culpaba al cómic y a otras formas de cultura popular de la ola de violencia juvenil en los años cincuenta. Frente a la peregrina, pero insistente teoría de que se actúa en función de lo que se lee y de que un público tarado está dispuesto a hacer realidad las más disparatadas ficciones, Neuróptica reivindicaba la fijación obsesiva por la imagen, la contemplación extasiada de la viñeta en sus esplendorosos detalles, la lectura en sus más encriptados matices de una figuración bulliciosa y desbordante de sentido. Neuróptica no era un argumentario para prohibir sino un manual para ver, para apreciar las sutilezas de lo dibujado. Neuróptica sólo era manifestación de la cada vez más extendida «neuropsis».

A ese mismo impulso obedeció Comicsarías, el libro sobre la historieta española de 1977 a 1987 que publiqué con Antoni Remesar. Aquí tampoco se trataba de hacer un chiste sobre el cómic, sino de denunciar barrotes y grilletes comerciales, editoriales, creativos que encerraban a un medio repleto de posibilidades. En 1987, fecha de publicación de Comicsarías, ya se veía el declinar de una etapa, en apariencia dorada, que apenas duró un lustro, el «boum» del cómic. Se intuía la necesidad de dar el salto que permitiera desarrollar esas latencias, incluso ya esas realidades. Así que no era broma. La historieta española se encontraba detenida en una «comicsaría» e intentábamos, si no sacarla de ahí, al menos denunciarlo.

Los tiempos han cambiado. Casi cuarenta años después de empezar a ser «neuróptico» no se juega tanto con las palabras, quizá las palabras (o sus usuarios) no se prestan a tanto juego. Puede que sea porque la lectura obsesiva de tebeos ya no se considera una ocurrencia léxica sino una realidad cada vez más extendida. Los «neurópticos» somos ahora legión y disfrutamos con ese laberíntico paseo por el grafismo y con la deglución compulsiva de bocadillos. Así que, después de tanto tiempo de haberle dicho adiós, ahora más que nunca, volvemos a darle la bienvenida. Aquí está, de nuevo, Neuróptica. 
Cuando apareció el primer número en octubre de 1983, con la financiación del Ayuntamiento de Zaragoza, escribí un prólogo que ya desde el título, «Dioptrías para impertinentes», mantenía el juego de palabras. Pero no había diletantismo sino, ante todo, voluntad, quizá necesidad. Necesidad de una publicación que estuviera a la altura de lo que el cómic ya estaba haciendo. Yo vivía con un pie en la Universidad y otro en los guiones que en aquella época escribía para Luis Royo. Hacía un par de años que había defendido una tesis sobre el cómic francófono y me parecía necesario que esta forma de expresión tuviera un lugar amplio, digno, divertido al tiempo que innovador, para su análisis. El formato de la revista universitaria parecía convenir no sólo para dar «categoría» al tebeo sino para ofrecerle un espacio que permitiera superar la reseña puntual a la que, en aquellos años, por los formatos editoriales y los intereses del público, estaba condenado. Se trataba de dar un paso más en el camino que ya recorrían Bang!, El Wéndigo, Sunday y otras publicaciones de crítica especializada. El objeto de estudio lo merecía y en España existía, desde hacía tiempo, el conocimiento para abordarlo. Los primeros síntomas de la crisis de las revistas de cómics y los inextricables designios de las instituciones aragonesas obligaron al cierre de Neuróptica en 1988, con cinco números publicados.

No sólo pretendió ampliar el espacio y reforzar el rigor del discurso crítico sino también ofrecer un producto ameno. El formato cuadrado, inusual en aquella época, permitía márgenes anchos para poblarlos de ilustraciones que reforzaran los argumentos de los artículos o, simplemente, reenviaran a la abundante y muy divertida reflexión que el medio mantenía sobre su historia y sus posibilidades expresivas. En este sentido no puedo dejar de mencionar la aportación fundamental de Paco Boisset, de Sansueña Industrias Gráficas, que se implicó en tareas de diseño y maquetación. Salvo el primer número que se tiró a mil ejemplares, los demás alcanzaron los mil quinientos, vendiéndose casi en su totalidad. Lo cual, para la época, incluso en el momento actual, resulta una cifra nada despreciable. La incorporación de la Diputación Provincial de Zaragoza a la financiación hizo posible estos cinco años gozosos, que ahora, casi como milagro, resucitan.

Había otros planteamientos básicos de los que la revista no se desmarcó en toda su trayectoria. No sólo invitaba a participar a críticos sino también a autores para que trasladaran una reflexión sobre su propio trabajo. Y allí estuvieron Beroy, Federico del Barrio, Felipe Hernández Cava, Garcés, Onliyú, Beà, Padu, Andreu Martín, Miguel Ángel Nieto, Tha, Juan Sasturaín, Fernando Fernández... Pude contar con las firmas desinteresadas de Vázquez 
de Parga, Antonio Lara, Ludolfo Paramio, Toni Guiral, Joan Navarro, Iván Tubau, Joaquín Dols, Mercedes Fernández, Antoni Remesar... Y hasta nos permitimos algunas estrellas foráneas, fundamentalmente del mundo francófono (franceses, belgas y canadienses), Antoine Roux, Guy Gauthier, Jacques Samson, Alain Chante, Yves Lacroix, André Simon, Jean-Claude Faur, Gérard Zureddu, Jacques Cohen...

El material del que se nutría cada número partía de las conferencias impartidas durante las Jornadas Culturales del Cómic de Zaragoza que se celebraron en esos mismos años. Pero, a partir del segundo número, surgió la posibilidad de completar temáticamente estas charlas, componiendo dosieres que permitieran un recorrido más plural y profundo sobre cada cuestión. Nos encontramos así con diversificadas reflexiones sobre «subvención y política institucional», «guion», «Hergé», «Ranxerox»... Y, quizá, con la perspectiva, uno de los proyectos más exquisitos, un recortable confeccionado por Christian-Marie Pons, titulado «Juan, el inocente», cuyo recortado, muy pocas veces realizado (me consta), proporciona uno de los cómics más admirables, todavía hoy, desde un punto de vista formal y de la construcción de la página.

Julio Andrés Gracia, doctor en cómic por la Universidad de Zaragoza, tuvo la idea de reflotar una empresa que languidecía bajo el polvo de los años. A partir de ahora Neuróptica es cosa suya. Y de los Comités Científicos, de Redacción, Asesores y, sobre todo, de los colaboradores, que se encargarán de generar una línea editorial acorde con los nuevos tiempos, más exigentes, más ricos y mucho más diversos de los que corrían en aquellos ochenta. A mí me queda la satisfacción de que aquel camino, con las convenientes reorientaciones, todavía resulte transitable. Orgulloso o, mejor dada la ocasión, henchido como un globo, me voy por los aires. Lo hago convencido de que la fijación obsesiva por las imágenes, la «neuropsis», crece y, poco a poco, se apodera del mundo. Por eso Neuróptica será, en esta su segunda época, más necesaria y, sobre todo, mejor que nunca. 